\title{
Schottky Barrier Height Engineering of Ti/n-Type Silicon Diode by Means of Ion Implantation
}

\author{
Doldet TANTRAVIWAT ${ }^{1,2,3, *}$, Wittawat YAMWONG ${ }^{3}$, \\ Udom TECHAKIJKAJORN ${ }^{3}$, Kazuo IMAI ${ }^{3}$ and Burapat INCEESUNGVORN ${ }^{2,4}$ \\ ${ }^{I}$ Department of Electrical Engineering, Faculty of Engineering, Chiang Mai University, \\ Chiang Mai 50200, Thailand \\ ${ }^{2}$ Center of Excellence in Materials Science and Technology, Materials Science Research Center, \\ Chiang Mai University, Chiang Mai 50200, Thailand \\ ${ }^{3}$ Thai Microelectronics Center (TMEC), National Electronics and Computer Technology Center, \\ Chachoengsao 24000, Thailand \\ ${ }^{4}$ Department of Chemistry, Faculty of Science, Chiang Mai University, Chiang Mai 50200, Thailand
}

('Corresponding author's e-mail: doldet.tantraviwat@cmu.ac.th)

Received: 31 October 2017, Revised: 26 January 2018, Accepted: 7 March 2018

\begin{abstract}
Herein, boron implantation technique was employed to engineer the Schottky barrier height (SBH) of Ti/n-type silicon junction (Ti/n-Si). The Ti/n-Si Schottky diodes with boron doses of 4, 5.4 and $6.6 \times 10^{12} \mathrm{~cm}^{-2}$ at the energy of $25 \mathrm{keV}$ were fabricated with improved rectification and their effective SBHs increased from 0.49 to 0.95 . The tuning of the effective SBH is mainly attributed to the presence of shallow p-layer, which modifies the energy band at $\mathrm{Ti} / \mathrm{n}$-Si interface. This work clearly shows that the ability to precisely control the $\mathrm{SBH}$, regardless of the metal work function, would facilitate the implementation of Schottky diode into various semiconductor structures, such as MPS (Merged PiN Schottky) diode, in order to improve performance without major modification on the existing metal line process.
\end{abstract}

Keywords: Schottky diode, Schottky barrier engineering, shallow implantation, titanium

\section{Introduction}

The rectifying behavior of Schottky diode generally depends on the Schottky barrier height (SBH), which is theoretically the difference between the metal work function and the electron affinity of the semiconductor. However, the investigation on a number of metal/semiconductor diodes reveals a narrow range of the SBH values with a weak correlation to the metal work function [1]. The limited range of the $\mathrm{SBH}$ values presents a challenge in exploitation of Schottky diode in semiconductor device structures for performance enhancement. It has been recently demonstrated that the incorporation of Schottky contacts, which has the $\mathrm{SBH}$ values in the range of $0.2-0.8 \mathrm{eV}$ [2], in the anode area can reduce the switching loss of power diode by suppressing an injection of holes into the $\mathrm{n}^{-}$drift region. The ability to accurately engineer the SBH, regardless of the metal work function, would allow manufacturers to improve power diode performance without major modification on their metal line process, which would have incurred a huge investment.

Selected papers from The $1^{\text {st }}$ MRS Thailand Conference, October $31^{\text {st }}-$ November $3^{\text {rd }}, 2017$ 
http://wjst.wu.ac.th

To achieve a wide range of the SBHs, several approaches have been explored in order to obtain greater control over the SBHs, such as the insertion of thin insulation layer between metal and silicon $[3,4]$, and the band structure engineering utilizing ion implantation. As the insertion of ultrathin insulation layer requires a special and expensive instrument to obtain high reliability and reproducibility for largescale integration, the band structure engineering appears to be more suitable for our investigation. Ion implantation can be used to form lowly doped layer near the silicon surface [5] or create an interfacial dipole confined to the metal-silicon interface [6-9]. This technique modifies the energy band diagram of silicon near the metal/silicon interface in relation to the metal Fermi level. Importantly, an implementation of band structure engineering does not require major modification of device fabrication because boron, arsenic and phosphorus are common dopants in modern CMOS technology. This simple and effective technique can also be easily integrated into the traditional diode fabrication process.

Although boron has been applied to create an interfacial dipole layer at the metal silicide/silicon interface [10], it has never been used, to the best of our knowledge, to engineer the SBH of Ti/n-type silicon (Ti/n-Si) diode. Herein, the formation of shallow p-layer with the different implanted boron doses is investigated with an emphasis on the modification of the effective $\mathrm{SBH}$ of a Ti/n-Si diode. By varying boron doses, the effective SBH can be adjusted and the tunable SBH value can be obtained in this present work.

\section{Materials and methods}

Figure 1 shows the energy band diagram, simulated using Sentaurus TCAD without Fermi level pinning consideration, for $\mathrm{Ti} / \mathrm{n}-\mathrm{Si}$ diode with and without boron implant. Boron doses of $4,5.4$ and $6.6 \times 10^{12} \mathrm{~cm}^{-2}$ with an implant energy of $25 \mathrm{keV}$ were used as implantation conditions. The presence of $100 \mathrm{~nm}$ thick p-layer from the $\mathrm{Ti} / \mathrm{Si}$ interface modifies the valance and conduction bands of silicon in relation to the titanium Fermi level, thus increasing the effective $\mathrm{SBH}$ of the diodes. Based on the simulation data, Ti/n-Si diodes implanted with boron doses of $4,5.4$ and $6.6 \times 10^{12} \mathrm{~cm}^{-2}$ at the energy of 25 $\mathrm{keV}$ were also fabricated using FZ NTD n-type silicon (100) substrates with resistivity of $60 \Omega \cdot \mathrm{cm}$.

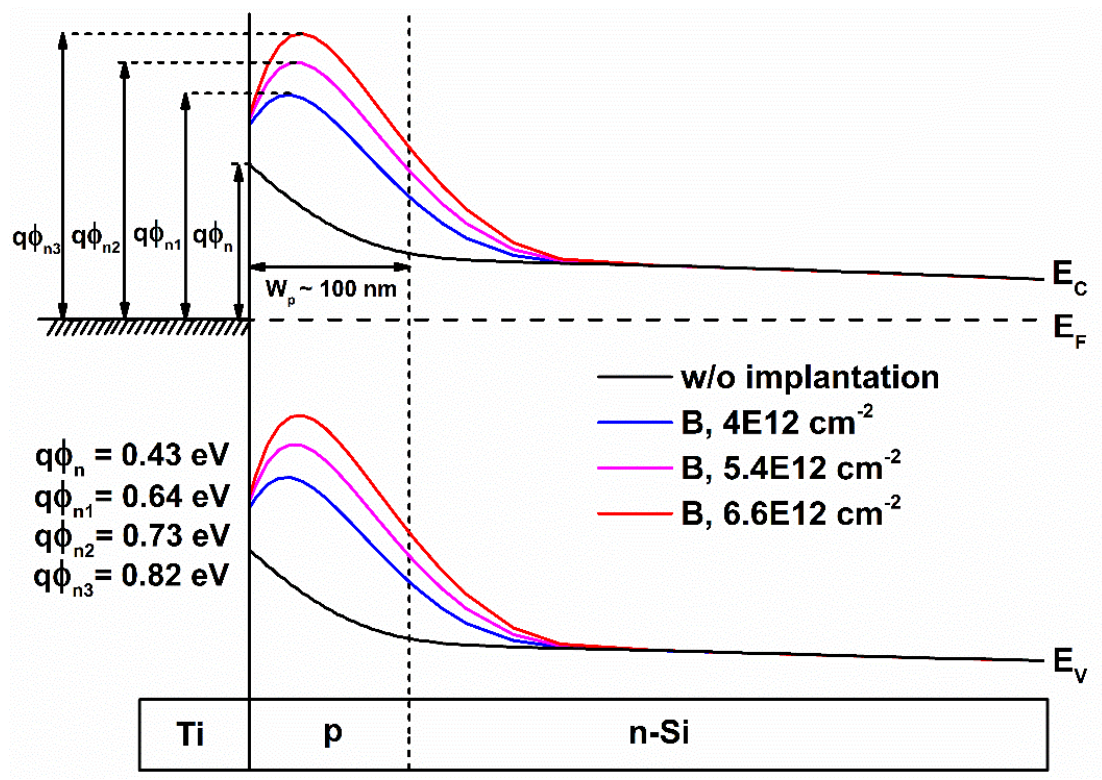

Figure 1 Simulated energy band diagram of a Ti/n-Si diode with and without implanted boron doses of 4 , 5.4 and $6.6 \times 10^{12} \mathrm{~cm}^{-2}$ at the energy of $25 \mathrm{keV} . \mathrm{W}_{\mathrm{p}}$ is the thickness of the p-implanted layer estimated to be $100 \mathrm{~nm}$. 
After the RCA cleaning process, the dry oxidation process was carried out to produce silicon dioxide $\left(\mathrm{SiO}_{2}\right)$ with a thickness of $110 \mathrm{~nm}$. Phosphorus was then implanted with doses of $8 \times 10^{13}$ and $5 \times 10^{11} \mathrm{~cm}^{-2}$ at energies of 1 and $0.25 \mathrm{MeV}$ with $7^{\circ}$ tilt, respectively. The purpose of phosphorus implant was to imitate an impurity profile of power diode device that is currently under our study. After that, the substrates were cleaned using piranha and standard clean (SC1) solutions. The phosphorus dopants were subsequently activated at $950{ }^{\circ} \mathrm{C}$ for $23 \mathrm{~min}$. The 3 diode samples were implanted with boron doses of 4 , 5.4 and $6.6 \times 10^{12} \mathrm{~cm}^{-2}$ at the energy of $25 \mathrm{keV}$ with $7^{\circ}$ tilt, resulting in a peak concentration close to the $\mathrm{SiO}_{2} / \mathrm{Si}$ interface. Another sample without boron implantation was used as control sample. The diode samples implanted with boron were activated by rapid thermal annealing (RTA) for $30 \mathrm{~s}$ at $950{ }^{\circ} \mathrm{C}$ in order to achieve shallow p-layer. The depth profiles of boron and phosphorus measured by secondary ion mass spectrometry (SIMS) indicates that thickness of p-layer is around $145 \mathrm{~nm}$ from the $\mathrm{SiO}_{2} / \mathrm{Si}$ interface (Figure S1), which is comparable with the simulation result. A $30 \mathrm{~nm}$ Ti film was deposited on silicon surface to form Schottky-barrier contact after the $\mathrm{SiO}_{2}$ was patterned and chemically removed from all samples. The active area of Ti/n-Si diodes was around $9 \times 10^{-4} \mathrm{~cm}^{2}$. A $500 \mathrm{~nm} \mathrm{Al} \mathrm{film} \mathrm{was} \mathrm{then} \mathrm{deposited}$ on top of the Ti layer in order to reduce the sheet resistance. Al film was also deposited on the backside after oxide removal to provide a backside ohmic contact. Finally, these samples were sintered at $450{ }^{\circ} \mathrm{C}$ for $30 \mathrm{~min}$ in forming gas.

Current-Voltage (I-V) measurements were carried out on these diodes at the different temperatures ranging from room temperature to $80{ }^{\circ} \mathrm{C}$ and the effective $\mathrm{SBH}$ was calculated based on the thermionicemission theory. The relationship between current and voltage can be expressed as [11-13]

$$
I=I_{s} \exp \left(q V_{D} / n k T\right)
$$

where $q$ is the elementary charge, $k$ is the Boltzmann constant, $T$ is the absolute temperature, $n$ is the ideality factor and $V_{D}$ is the voltage applied across the diode. $I_{s}$ is the reverse saturation current defined as

$$
I_{s}=A A^{*} T^{2} \exp \left(-q \varphi_{B n} / k T\right)
$$

where $A$ is the diode contact area, $A^{*}$ is the Richardson constant and $\phi_{B n}$ is the Schottky barrier height for electrons. The Eq. (2) can also be rewritten as

$$
\ln \left(\frac{I_{s}}{A A^{*} T^{2}}\right)=-\frac{q \phi_{B n}}{k T}
$$

According to Eq. (3), the $\ln \left(\mathrm{I}_{\mathrm{s}} / \mathrm{T}^{2}\right)$ and $1 / \mathrm{T}$ plot should provide a straight line with the slope yielding the effective SBH.

\section{Results and discussion}

Figure 2 shows the room temperature I-V characteristics of Ti/n-Si Schottky diode fabricated with and without boron implantation. Without boron implant, typical Schottky diode characteristics are observed. It can be seen that improved rectification is obtained for diode samples with boron implant. For samples with the boron doses of 4 and $5.4 \times 10^{12} \mathrm{~cm}^{-2}$, the reverse currents are significantly decreased, while the forward currents are slightly affected. Furthermore, as the Ti/n-Si diode implanted with boron dose of $6.6 \times 10^{12} \mathrm{~cm}^{-2}$ exhibits the highest turn on voltage, its forward and reverse currents are found to be around one and seven orders of magnitude lower than those of the unimplanted diodes, respectively. The 
http://wjst.wu.ac.th

reduction of forward and reverse currents can be attributed to the increase of the effective SBHs of the diodes $[9,14,15]$. By extrapolating value of the forward current at zero bias in the semi-log I-V plot, the reverse saturation current $\left(\mathrm{I}_{\mathrm{s}}\right)$ is obtained and the effective SBH is extracted from Eq. (2).

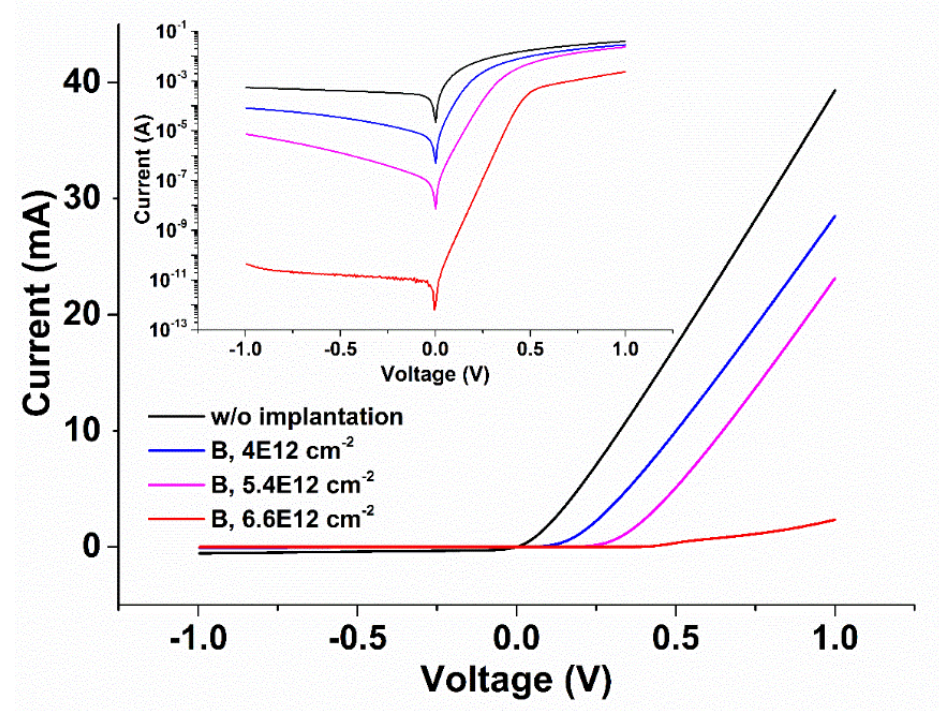

Figure $2 \mathrm{I}-\mathrm{V}$ characteristics of the Ti/n-Si didoes with and without boron implant in semi-log and linear scale. The active area of diode is $9 \times 10^{-4} \mathrm{~cm}^{-2}$.

As another approach in determining the $\mathrm{SBH}$, the $\mathrm{I}-\mathrm{V}$ characteristics are measured on all diode samples in the temperature range of 20 to $80{ }^{\circ} \mathrm{C}$ with a $10^{\circ} \mathrm{C}$ step. By obtaining the $\mathrm{I}_{\mathrm{s}}$ of diode samples for each temperature, a linear relationship between $\ln \left(\mathrm{I}_{\mathrm{s}} / \mathrm{T}^{2}\right)$ and $1 / \mathrm{T}$ can be established, which is demonstrated in Figure 3. It can be noticed from Figure 3 that the slope becomes steeper implying the increase of the effective $\mathrm{SBH}$ as the boron dose is increased. The effective SBHs determined from $\ln \left(\mathrm{I}_{\mathrm{s}} / \mathrm{T}^{2}\right)-1 / \mathrm{T}$ and $\mathrm{I}-\mathrm{V}$ plots and those obtained from the simulation as a function of boron doses are compared in Table 1. 


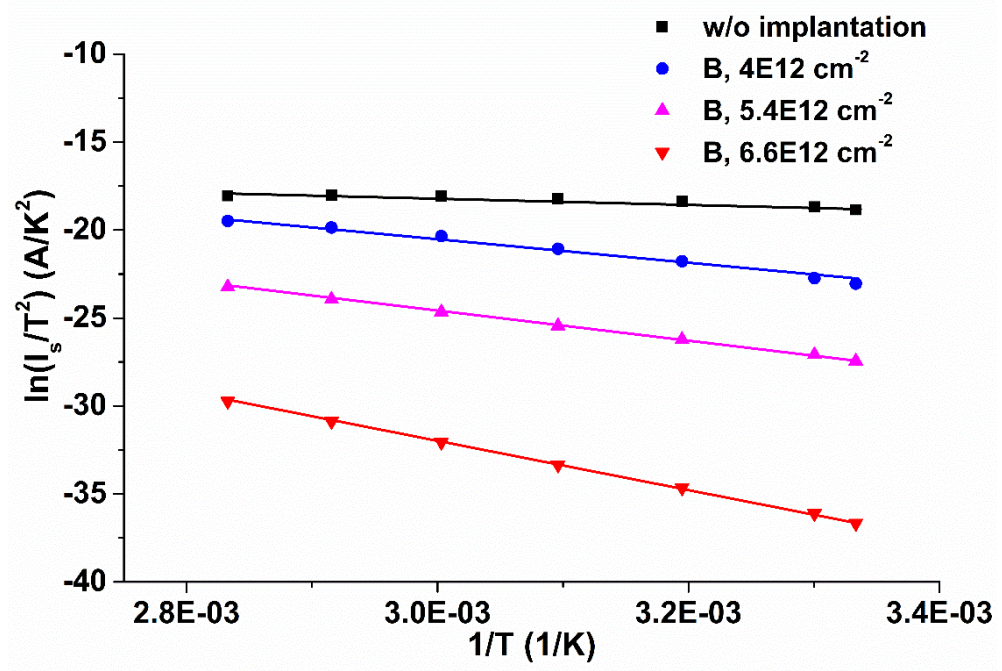

Figure $3 \ln \left(\mathrm{I}_{\mathrm{s}} / \mathrm{T}^{2}\right)-1 / \mathrm{T}$ characteristics of the $\mathrm{Ti} / \mathrm{n}-\mathrm{Si}$ didoes with and without boron implant. The measurement was carried out in the range of $20-80{ }^{\circ} \mathrm{C}$. The active area of diode is $9 \times 10^{-4} \mathrm{~cm}^{-2}$.

The extraction of the effective SBHs from the $\mathrm{I}-\mathrm{V}$ and $\ln \left(\mathrm{I}_{\mathrm{S}} / \mathrm{T}^{2}\right)-1 / \mathrm{T}$ characteristics for Ti/n-Si diodes without boron implant yields the values of 0.49 and $0.41 \mathrm{eV}$, respectively. These values are consistent with the one reported previously [16]. Jyothi et al. [17] and Ohta et al. [18] have also reported the SBH of Ti/p-type silicon (p-Si) junction to be around 0.7 . As the sum of the SBH on n-Si $\left(\phi_{B n}\right)$ and the SBH on p-Si $\left(\phi_{B p}\right)$ theoretically equals to the band gap of silicon $(\sim 1.1 \mathrm{eV})$, the resulting $\phi_{B n}$ values from their studies $(\sim 0.4 \mathrm{eV})$ are also in line with our extracted values. It can be observed from Table 1 that the effective SBH enhances upon increasing boron doses. The effective SBHs extracted from the measurement data are also in agreement with those obtained from the calculation of the energy band diagram.

Table 1 Comparison of the extracted SBHs and the values obtained from the simulation as a function of boron doses for $\mathrm{Ti} / \mathrm{n}-\mathrm{Si}$ diodes.

\begin{tabular}{cccc}
\hline $\begin{array}{c}\text { Boron dose } \\
\left(\times \mathbf{1 0}^{\mathbf{1 2}} \mathbf{c m}^{-\mathbf{2}}\right)\end{array}$ & \multicolumn{3}{c}{ The effective SBHs $(\mathbf{e V})$} \\
\cline { 2 - 4 } & $\mathbf{I}-\mathbf{V}$ & $\ln \left(\mathbf{I}_{\mathbf{s}} / \mathbf{T}^{\mathbf{2}}\right)-\mathbf{1} / \mathbf{T}$ & Calculated \\
\hline 0 & 0.49 & 0.41 & 0.43 \\
4 & 0.60 & 0.62 & 0.64 \\
5.4 & 0.71 & 0.72 & 0.73 \\
6.6 & 0.95 & 1.18 & 0.82 \\
\hline
\end{tabular}

However, the discrepancy of the effective SBHs is observed for the diode with a boron dose of $6.6 \times 10^{12} \mathrm{~cm}^{-2}$ where the effective SBHs of 0.95 and $1.18 \mathrm{eV}$ are calculated from the $\mathrm{I}-\mathrm{V}$ and $\ln \left(\mathrm{I}_{\mathrm{s}} / \mathrm{T}^{2}\right)-1 / \mathrm{T}$ characteristics, respectively. Since the SBH extraction is theoretically based on the saturation current $\left(\mathrm{I}_{\mathrm{s}}\right)$, a possible reason for the deviation of the extracted SBHs could be found upon considering the saturation current model of p-n junction compared with that of Schottky contact. Sze [13] has shown that temperature dependence of the saturation current of p-n junction is given by $I_{s} \alpha T^{(3+\gamma / 2)} \exp \left(-E_{g} / k T\right)$ where $\gamma$ is a constant and $E_{g}$ is the energy gap. On the contrary, the temperature effect on the saturation current of Schottky contact is given by $I_{s}=A A^{*} T^{2} \exp \left(-q \phi_{B n} / k T\right)$. The terms of $T^{(3+\gamma / 2)}$ and $T^{2}$ from both equations are less important than the exponential term [13]. Therefore, it is expected that the slope of $\ln \left(\mathrm{I}_{\mathrm{s}} / \mathrm{T}^{2}\right)$ 
http://wjst.wu.ac.th

versus $1 / \mathrm{T}$ is determined by the energy gap and the SBH for $\mathrm{p}-\mathrm{n}$ junction and Schottky diode, respectively. As the value of $1.18 \mathrm{eV}$ extracted from the slope of $\ln \left(\mathrm{I}_{\mathrm{s}} / \mathrm{T}^{2}\right)-1 / \mathrm{T}$ plots for diode implanted with the boron dose of $6.6 \times 10^{12} \mathrm{~cm}^{-2}$ is close to the value of silicon energy band gap, it is believed that this particular diode behaves like a p-n junction rather than a Schottky contact, which potentially causes deviation from the thermionic-emission theory. It therefore leads to an inaccurate SBH extraction from both the $\mathrm{I}-\mathrm{V}$ and $\ln \left(\mathrm{I}_{\mathrm{s}} / \mathrm{T}^{2}\right)-1 / \mathrm{T}$ plots. These results also imply that there is limitation on a range of SBH that can be obtained using shallow implantation technique.

\section{Conclusions}

Boron implantation has been experimentally investigated as a $\mathrm{SBH}$ engineering technique to enhance the effective SBH of Ti/n-Si diodes. By implanting boron doses of 4 and $5.4 \times 10^{12} \mathrm{~cm}^{-2}$ at $25 \mathrm{keV}$ energy with $7^{\circ}$ tilt, the effective SBHs extracted from the $\mathrm{I}-\mathrm{V}$ and $\ln \left(\mathrm{I}_{\mathrm{s}} / \mathrm{T}^{2}\right)-1 / \mathrm{T}$ characteristics are approximately 0.6 and $0.7 \mathrm{eV}$, respectively. The differences of the $\mathrm{SBH}$ values observed from the diode with boron dose of $6.6 \times 10^{12} \mathrm{~cm}^{-2}$ are attributed to a deviation of the diode characteristics from the thermionic-emission theory, which results in an inaccurate SBH extraction. The SBH tuning effect is due to the modification of energy band near silicon surface induced by shallow p-layer. However, it is unlikely that the SBH higher than $0.7 \mathrm{eV}$ can be achieved using this technique due to the formation of a p-n junction, rather than a Schottky contact.

\section{Acknowledgements}

This work was supported by the Thailand Research Fund and Commission on Higher Education, (Grant no. MRG6080098), the Center of Excellence in Materials Science and Technology, Materials Science Research Center, Chiang Mai University, the Center for Innovation in Chemistry (PERCH-CIC), Ministry of Education and Thai microelectronics Center (TMEC).

\section{References}

[1] N Newman, MV Schilfgaarde, T Kendelwicz, MD Williams and WE Spicer. Electrical study of Schottky barriers on atomically clean GaAs (110) surface. Phys. Rev. B 1986; 33, 1146-59.

[2] Y Yamashita, S Machida, T Sugiyama and J Saito. Kanushiki Kaisha Toyota Chuo Kenkyusho, Toyota Jidosha Kabushiki Kaisha. Diode, Semiconductor Device, and MOSFET. World Intellectual Property Organization WO 2013/014943 A2.

[3] WC Huang, TC Lin, CT Hong and CC Chen. Barrier heights engineering of Al/p-Si Schottky contact by a thin organic interlayer. Microelec. Eng. 2013; 107, 200-4.

[4] M Tao, D Udeshi, N Basit, E Maldonado and WP Kirk. Removal of dangling bonds and surface states on silicon (001) with a monolayer of selenium. Appl. Phys. Lett. 2003; 82, 1559.

[5] SS Li, JS Kim and KL Wang. Enhancement of effective barrier height in Ti-silicon Schottky diode using low-energy ion implantation. IEEE Tran. Elec. Dev. 1980; 27, 1310-2.

[6] QT Zhao, U Breuer, E Rije, S Lenk and S Mantl. Tuning of NiSi/Si Schottky barrier heights by sulfur segregation during Ni silicidation. Appl. Phys. Lett. 2005; 86, 062108.

[7] Z Zhang, Z Qui, R Liu, M Ostling and SL Zhang. Schottky-barrier height tuning by means of ion implantation into preformed Silicide films followed by drive-in anneal. IEEE Elec. Dev. Lett. 2007; 28, 565-8.

[8] E Alptekin, MC Ozturk and V Misra. Tuning of the Platinum Silicide Schottky barrier height on ntype Silicon by Sulfur segregation. IEEE Elec. Dev. Lett. 2009; 30, 331-3.

[9] SM Koh, X Wang, T Thanigaivelan, T Henry, Y Erokhin, GS Samudra and YC Yeo. Schottky barrier height tuning of silicides on p-type Si (100) by aluminum implantation and pulsed excimer laser anneal. J. Appl. Phys. 2011; 110, 073703.

[10] F Ravaux, E Dubois and Z Chen. Schottky barrier height reduction using strained Silicon-OnInsulator and dopant segregation. Microelec. Eng. 2012; 98, 391-4. 
http://wjst.wu.ac.th

[11] E H Rhoderick and R H Williams. Metal-Semiconductor Contacts. $2^{\text {nd }}$ eds. Clarendon Press, Oxford, 1988.

[12] G Mohammad, R Khairunisak and C Kuan. Schottky barrier height engineering of Al contacts on Si by embedded Au nanoparticles. Microelec. Eng. 2015; 113, 110-9.

[13] SM Sze and KK Ng. Physics of Semiconductor Devices. $3^{\text {rd }}$ eds. Wiley-Interscience, New Jersey, 2007.

[14] M Mueller, QT Zhao, C Urban, C Sandow, D Buca, S Lenk, S Estevez and S Mantl. Schottkybarrier height tuning of NiGe/n-Ge contacts using As and P segregation. Mater. Sci. Eng. B 2008; 154-155, 168-71.

[15] BE Coss, WY Loh, RM Wallace, J Kim, P Majhi and R Jammy. Near band edge Schottky barrier height modulation using high-K dielectric dipole tuning mechanism. Appl. Phys. Lett. 2009; 95, 222105.

[16] AM Cowley. Titanium-silicon Schottky barrier diodes. Solid-State Electron. 1970; 13, 403-14.

[17] I Jyothi, HD Yang, KH Shim, V Janardhanam, SM Kang, H Hong and CJ Choi. Temperature dependency of Schottky barrier parameters of Ti Schottky contacts to Si-on-insulator. Mater. Trans. 2013; 54, 1655-60.

[18] RL Ohta, CE Viana, NI Morimoto and BV Borges. Fabrication of Ti-Si-Ti metal-semiconductormetal photodetectors using low temperature rapid thermal annealing. J. Integr. Circuits Syst. 2007; 2, 85-8. 